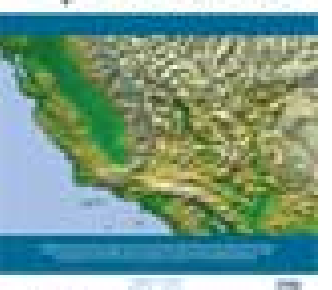

\title{
Assessing the impact of bridge construction on the land use/cover and socio-economic indicator time series: A case study of Hangzhou Bay Bridge
}

\author{
Lixia Chu , Yuting Zou , Dainius Masiliūnas , Thomas Blaschke \& Jan \\ Verbesselt
}

To cite this article: Lixia Chu, Yuting Zou, Dainius Masiliūnas, Thomas Blaschke \& Jan Verbesselt (2021): Assessing the impact of bridge construction on the land use/cover and socioeconomic indicator time series: A case study of Hangzhou Bay Bridge, GIScience \& Remote Sensing, DOI: $10.1080 / 15481603.2020 .1868212$

To link to this article: https://doi.org/10.1080/15481603.2020.1868212
(c) 2021 The Author(s). Published by Informa UK Limited, trading as Taylor \& Francis Group.

曲 Published online: 17 Jan 2021.

Џll Article views: 201

View Crossmark data $\rtimes$
+ View supplementary material $\longleftarrow$

Submit your article to this journal $\pi$ 


\title{
Assessing the impact of bridge construction on the land use/cover and socio- economic indicator time series: A case study of Hangzhou Bay Bridge
}

\author{
Lixia Chu $\mathbb{D D}^{\mathrm{a}}$, Yuting Zou $\mathbb{D}^{\mathrm{b}}$, Dainius Masiliūnas $\mathbb{D}^{\mathrm{b}}$, Thomas Blaschke $\mathbb{D}^{\mathrm{a}}$ and Jan Verbesselt $\mathbb{D}^{\mathrm{b}}$ \\ aDepartment of Geoinformatics - Z_GIS, University of Salzburg, Salzburg, Austria; bLaboratory of Geo-information Science and Remote \\ Sensing, Department of Environmental Sciences, Wageningen University \& Research, Wageningen, The Netherlands
}

\begin{abstract}
Construction of transportation infrastructure is a vital step in boosting economic and societal opportunities and often results in land use changes. In this study, we focus on the land use dynamics of the urban agglomeration around Hangzhou Bay, where the Qiantang River flows into the East China Sea. The Hangzhou Bay Bridge crosses the bay since 2008. We used Interrupted Time Series Analysis (ITSA) to analyze the influence of the bridge on the land use and land cover (LULC) time series of the surrounding areas and on socio-economic indicators. We applied the Random Forest method to classify Landsat imagery from 2000 to 2017, thus enabling us to quantify LULC changes before and after the construction of the Hangzhou Bay Bridge. Google Earth Engine (GEE) was used for data acquisition, pre-processing, and classification. The results showed that during the period from 2000 to 2017, impervious surface areas expanded rapidly at the expense of agricultural land, and this transformation continued even more rapidly after 2008. ITSA showed that the driver behind the impervious surface area expansion switched from residential and industrial area growth in 2000-2008, to exclusively infrastructure area growth in 2008-2017. The construction of the bridge accelerated the expansion of impervious surface in the joint area of the bridge-connected cities of Ningbo and Jiaxing. With the Hangzhou Bay Bridge connection, various socio-economic factors, including tourism, GDP, tertiary industry, real estate investment, and highway freight, increased rapidly. The outcomes of this research could contribute to policymaking and impact assessments for sustainable urban development and land management. The methods used in this study are universal and therefore can also be used to assess the effect of any notable event that may impact LULC change.
\end{abstract}

\section{ARTICLE HISTORY}

Received 28 July 2020

Accepted 18 December 2020

\section{KEYWORDS}

Land use/cover time series; socio-economic indicators; bridge construction; interrupted time series analysis; random forest; google Earth Engine

\section{Introduction}

Human activities consistently shape landscapes, transform land use, and influence socio-economic development through urban expansion, agriculture intensification, infrastructural developments, and natural resource exploration. In most countries around the world, cities with well-developed transportation infrastructure spur regional development and attract local capital and global investment (Shahtahmassebi et al. 2018; Lein and Day 2008; Zheng et al. 2016; Yavuz, Attanayake, and Aktan 2017; Thomas and Daniel 2013). Well-developed transport infrastructure can boost economic and societal opportunities through the process of industrialization and urbanization (Cai, Zhifeng, and Cheng 2013; Aa and Rich 2013; Lin 1999). The coastal plains and active estuaries, especially bays and lagoons, usually serve as a significant economic resource, supporting agriculture, fishing, transportation, mining, and tourism sub-sectors. However, as land resources are limited, these areas are put under pressure to sustain vulnerable ecosystem protection and still fuel economic development (McLean et al. 2001; Cui et al. 2015; Chen et al. 2005; Tian et al. 2016; Hagenaars et al. 2017; Halpern et al. 2008). In these areas, land use and land cover (LULC) changes rapidly, particularly after the completion of large infrastructure projects such as the building of a sea-cross bridge. Bridges play a role in connecting urban agglomerations, hastening urban and rural sprawl, promoting industry, tourism and other socio-economic development, but they also affect the local ecosystems (Disperati and Salvatore Gonario 2015). The analysis of such bridge construction events is important as it provides insight into the physical, social and economic changes that follow them. 
We selected the Hangzhou Bay agglomeration, consisting of four prefecture-level city municipalities (Ningbo, Jiaxing, Shaoxing and Hangzhou) of the Zhejiang province, as the research area for this study. This study focuses on the analysis of the influence of the opening of the Hangzhou Bay Bridge on the LULC of the area and the socio-economic indicators of the cities. Section 2 of this study describes the study area and the data used in more detail. Section 3 describes the workflow of this study: the preprocessing of features for use in the LULC classification models, the collection of training data for the models and the models themselves. The section also explains how the models were validated, and describes the statistical analysis of the model output and corresponding socio-economic data. In section 4, the results are presented: the output classified LULC maps, the accuracy of these maps, LULC change over time in our study area, and the links between socioeconomic factors and the opening of the Hangzhou Bay Bridge. Section 5 provides a discussion of the results by comparing this study and previous studies, discussing the LULC change trends identified based on the classified LULC maps and linking the opening of the bridge with LULC and socio-economic indicator change. It also includes an overview of the limitations of the study and potential for future research. Lastly, section 6 summarizes the findings.

Among the studies investigating the influence of bridge construction, some focused on assessing the influence of bridge construction on changes in builtup areas and socio-economic indicators (Xie et al. 2018; Long et al. 2007). A study on the influence of Hangzhou Bay bridge construction used three years of Landsat imagery to map the expansion of impervious surface in Cixi county of Ningbo city (Shahtahmassebi et al. 2018) and another assessed the influence of the bridge construction on the urban and social development in Cixi county (Zheng et al. 2016).

Most of the previous studies were limited in scope to only a comparison of a few years of LULC change thus limiting their ability to assess how both LULC and socio-economic factors evolved over time. Understanding the influence of transportation infrastructure construction on land use and socio-economic variables is important and deserves further research. Modern cloud computing platforms such as Google Earth Engine
(GEE) enable researchers to access multi-source data catalogs for geospatial analysis and provides the extensive computational capabilities needed to deal with a variety of societal and environmental issues at large scales (Gorelick et al. 2017). We used GEE to access and analyze Landsat image archives by running a random forest (RF) classification to obtain the time series of detailed LULC classes from 2000 to 2017. This enabled us to quantify the LULC dynamics and analyze the changes by comparing the LULC trends before and after the opening of the bridge. While the most common method of assessing LULC change is to perform single-date classification and then to do a post-classification analysis, we employed a more advanced approach in this study by performing annual LULC classifications and then analyzing the change trends, thus obtaining robust statistics that are not affected by interannual variability.

In addition, we adopted a statistical analysis method called Interrupted Time Series Analysis (ITSA) to track the effect of the bridge construction. ITSA is a quasi-experimental research design to track a time series before and after an intervention and assess the intervention effect. It has been widely used in the fields of economics and medicine (Linden 2015; Penfold and Zhang 2013; Lopez Bernal et al. 2013). For instance, ITSA has been used for evaluating the effectiveness of a new medicine or vaccines on population-level health. It has the advantage of minimizing the effect of confounding factors, in other words the influence of unmeasured factors or ones that cannot be included in the model explicitly, such as the influence of seasonality when evaluating new vaccines or medicine (Bernal, Cummins, and Gasparrini 2017). ITSA had not been applied to the LULC domain until now. The effect of bridge construction on LULC can be considered similar to that of a vaccine on public health. In addition, ITSA design requirements (the intervention, data and outcome requirements) make it appropriate for evaluating the influence of bridge construction on LULC changes (Bernal, Cummins, and Gasparrini 2017). Specifically, the method facilitates a LULC comparison with areas that are not affected by the bridge construction event, thus dealing with confounding effects of other factors that have not been 
included in the model explicitly. Therefore, we used the ITSA method in this study to evaluate the influence of the bridge construction on annual changes in LULC and socio-economic indicators in the urban agglomeration in Hangzhou Bay.

\section{Study area and data sources}

\subsection{Study area}

Hangzhou Bay urban agglomeration (Zhejiang, China) surrounding Hangzhou Bay Bridge was selected as the study area (Figure 1). The area covers a spatial extent of approximately $38,453 \mathrm{~km}^{2}$ and includes 36 counties within four prefectural-level city municipalities, that is, Hangzhou $\left(16,800 \mathrm{~km}^{2}\right)$, Jiaxing $\left(4,009 \mathrm{~km}^{2}\right)$, Shaoxing $\left(8,279 \mathrm{~km}^{2}\right)$ and Ningbo $\left(9,365 \mathrm{~km}^{2}\right)$. The combined total population of the area in 2017 was about 2,347 million people (Feng et al. 2017). The Hangzhou Bay Bridge, which crosses the Hangzhou Bay where the Qiantang River flows into the East China Sea, was constructed between June 2003 and June 2007. It is the third-longest ocean-crossing bridge in the world with an overall length of $36 \mathrm{~km}$. The construction of the bridge has brought about a series of LULC changes and promoted the socio-economic development in the area (Zheng et al. 2016; Shahtahmassebi et al. 2018). The area is mainly covered by forest, agriculture, and impervious land. The urban agglomeration in Hangzhou Bay has contributed significantly to the socio-economic wellbeing of the Zhejiang Province and China as a whole, with an increase in the gross domestic product (GDP) from 3,769 million CNY in 2000 to 31,904 million CNY in 2017 (Feng et al. 2017).

\subsection{Data sources}

Four types of data were used in this study: Landsat imagery, ancillary datasets, LULC reference maps, and statistical yearbook data (see Table 1). Landsat datasets were used to generate the annual time series from 2000 to 2017, which served as the basis for the LULC classification. Ancillary datasets, including Global Surface Water occurrence (Pekel et al. 2016) and Shuttle Radar Topography Mission (SRTM) digital elevation model (DEM) (Yang, Meng, and Zhang 2011), from the GEE platform, were used to improve the classification accuracy of LULC maps. Four land cover maps from two datasets (Chen et al. 2015; Gong et al. 2019) were used for the initial stratified random sampling of training points and for comparison with RF classification results as an additional point of reference for assessing the classification accuracy.

We acquired a time series of Landsat imagery from the Landsat image archives provided by the GEE

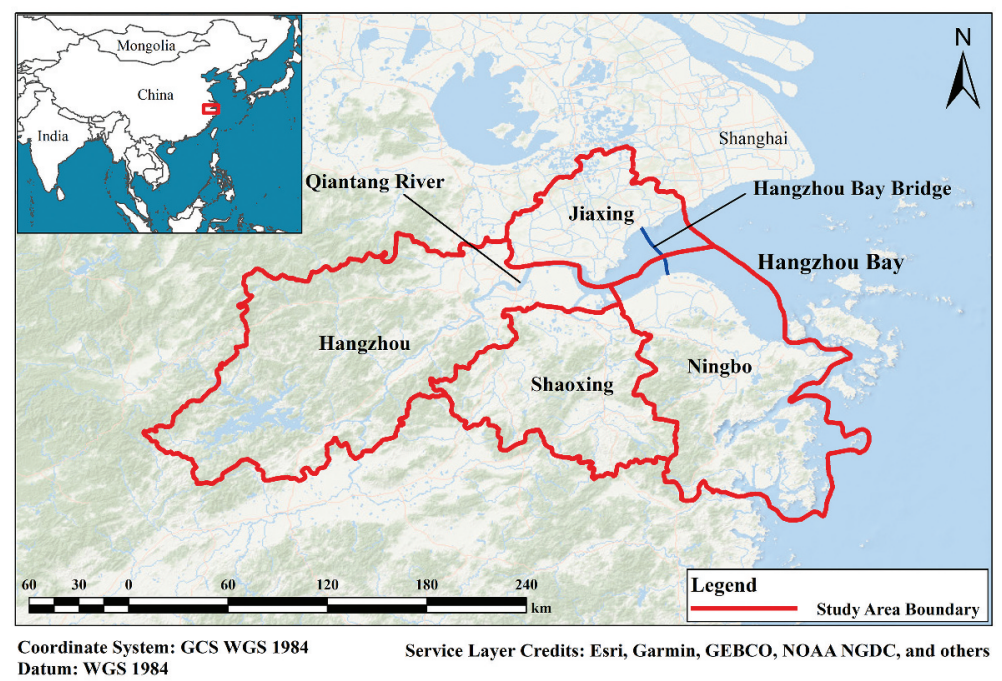

Figure 1. The location of the four prefecture-level city municipalities that comprise the study area, relative to the location of Hangzhou bay and the Hangzhou Bay Bridge. The base map is the World Ocean Basemap. 
Table 1. Overview of input datasets used in this research.

\begin{tabular}{|c|c|c|c|c|}
\hline Dataset name & & Year & Source / provider & $\begin{array}{l}\text { Detailed } \\
\text { information }\end{array}$ \\
\hline $\begin{array}{l}\text { Landsat 5, } 7 \text { (ETM+) } 30 \text { m (U. } \\
\text { S. Geological Survey } \\
\text { 2020a, 2020b) }\end{array}$ & $2000-2012$ & GEE & Time series for LULC classification & \\
\hline $\begin{array}{l}\text { Landsat } 8 \text { (OLI) } 30 \text { m (U.S. } \\
\text { Geological Survey 2020c) }\end{array}$ & $2013-2017$ & & & \\
\hline Features for classification & $2000-2017$ & $\begin{array}{l}\text { None; derived from the above Landsat data } \\
\text { using GEE }\end{array}$ & $\begin{array}{l}\text { Spectral features: } \\
\text { Band } 1 \text { to band } 7 \text { for Landsat } 5 \& 7 \text {; band } 2 \\
\text { to band } 7 \text { for Landsat } 8 \\
\text { Vegetation indices: } \\
\text { NDVI, EVI, NDBI, SAVI, MNDWI, LSWI } \\
\text { Texture features: } \\
\text { Angular Second Moment, contrast, } \\
\text { variance, correlation, inverse difference } \\
\text { moment, sum average, entropy, and } \\
\text { dissimilarity } \\
\text { Harmonic features: } \\
\text { Second-order harmonics: amplitude and } \\
\text { phase }\end{array}$ & \\
\hline $\begin{array}{l}\text { JRC Global Surface Water } \\
\text { Mapping Layers, v1.1 } \\
\text { (GSWM) (Pekel et al. } \\
\text { 2016) }\end{array}$ & $2000-2017$ & GEE & Occurrence layer, used in classification & \\
\hline $\begin{array}{l}\text { Shuttle Radar Topography } \\
\text { (SRTM) digital elevation } \\
\text { data } 30 \text { m (NASA JPL } \\
\text { 2013) }\end{array}$ & 2000 & & Elevation and slope data for classification & \\
\hline $\begin{array}{l}\text { LULC reference maps, } 30 \mathrm{~m} \\
\text { resolution } \\
\text { (Chen et al. 2015; Gong et } \\
\text { al. 2019) }\end{array}$ & $\begin{array}{l}2000,2010 \\
2015,2017\end{array}$ & $\begin{array}{c}\text { GLC30 } \\
\text { FROM-GLC }\end{array}$ & $\begin{array}{l}\text { Reference maps for LULC map comparison } \\
\text { and training sample stratification }\end{array}$ & \\
\hline $\begin{array}{l}\text { Socio-economic data (Feng } \\
\text { et al. 2017) }\end{array}$ & $2000-2017$ & $\begin{array}{c}\text { Annual statistics yearbook from Municipal } \\
\text { Statistics Bureau of Jiaxing, Shaoxing, } \\
\text { Ningbo and Hangzhou prefecture-level } \\
\text { cities }\end{array}$ & $\begin{array}{l}\text { Economics, food production, population, } \\
\text { tourism indicators }\end{array}$ & \\
\hline
\end{tabular}

platform: Landsat 7 ETM+ (2000-2002, 2012), Landsat 5 TM (2003-2011), and Landsat 8 OLI (2013-2017) surface reflectance Tier 1 datasets at $30 \mathrm{~m}$ resolution. These datasets had already been intercalibrated across the different Landsat instruments (Pinto et al. 2019) and corrected atmospherically using the LEDAPS (Masek et al. 2006) and LaSRC algorithms (Vermote et al. 2016). For this study, we used the cloud, shadow, water and snow mask generated by the CFMASK algorithm (Guo et al. 2020), that is already provided together with the products, to keep only clear pixels for further processing. We used Landsat 5 (TM) data to substitute Landsat 7 (ETM+) data from 2003 to 2011 to avoid data gaps owing to the Scanline Corrector (SLC) failure of Landsat $7($ ETM+) from 2003 onwards. There was no Landsat 5 (TM) imagery in 2012, so we used the Landsat 7 (ETM+) data for this year. The imagery for 2012 was used as-is without attempting to fill the SLCoff gaps.

In addition to using the Landsat imagery directly, we also used its time series to calculate vegetation indices, texture, and harmonic features, to improve the classifier performance (Halmy et al. 2015). The features derived from the Landsat datasets (Table 1) included Normalized Difference Vegetation Index (NDVI) (Tucker 1979), Enhanced Vegetation Index (EVI) (Liu and Huete 1995), Normalized Difference Built-up Index (NDBI) (Zha, Gao, and Shaoxiang 2003), Soil-adjusted Vegetation Index (SAVI) (Huete 1988), Modified Normalized Difference Water Index (MNDWI) (Xu 2006), and Land Surface Water Index (LSWI) (Chandrasekar et al. 2010).

In addition to Landsat derivatives, ancillary datasets were used to train the classifier on additional features. In particular, SRTM data (30 m spatial resolution) were used to obtain the elevation and slope (Colvocoresses 1981; Yang, Meng, and Zhang 2011), and water occurrence from the Joint Research Center (JRC) Global Surface Water Mapping Layers (GSWM) was used to improve the accuracy of water classification (Pekel et al. 2016).

Furthermore, we used reference LULC maps of four specific years for two purposes. First, we used the 
reference maps to stratify the study area and obtain the locations at which to collect training data for the $\mathrm{RF}$ model. Second, we used them to compare with the $\mathrm{RF}$ model output to assess the agreement between the two LULC maps as an indicator of accuracy for the maps classified by RF. The reference GLC30 maps for 2000 and 2010 are products derived from Landsat 5 Thematic Mapper (TM), Landsat $7(\mathrm{ETM}+)$, and the China Environmental Disaster Alleviation Satellite (HJ-1) imagery, with substantive auxiliary data (Chen et al. 2015). The reference FROM-GLC maps for the years 2015 and 2017 are products derived from Landsat Thematic Mapper (TM) and Enhanced Thematic Mapper Plus (ETM+) data (Gong et al. 2019).

Lastly, to investigate the influence of the bridge on human activities, based on previous studies, we selected 10 socio-economic indicators to represent three aspects: economics, tourism, and freight (Wu et al. 2013; Shahtahmassebi et al. 2018). We obtained these socio-economic indicators for 2000 to 2017 from the city yearbooks of the Municipal Statistics Bureaus of Jiaxing, Shaoxing, Ningbo, and Hangzhou city (Table 2).

\section{Methods}

The main methodological steps in this study comprised data acquisition, data pre-processing for classification, and data analysis. Figure 2 shows the overview of the workflow, with software and platforms used in this research.

Table 2. Socio-economic indicators used in this research. The time span of the data corresponds to the study period (2000-2017).

\begin{tabular}{llc}
\hline Socio-economic indicator & \multicolumn{1}{c}{ Short Name } & Unit \\
\hline Output Value of Primary Industry & Primary industry & $\begin{array}{c}100 \text { million } \\
\text { CNY }\end{array}$ \\
Output Value of Secondary Industry & $\begin{array}{c}\text { Secondary } \\
\text { industry }\end{array}$ & 100 million \\
CNY & Certiary industry & 100 million \\
Output Value of Tertiary Industry & CNY \\
Per Capita GDP & GDP & CNY \\
Household Registration Population & Population & 10,000 persons \\
Investment in Fixed Assets & Fixed assets & 100 million \\
& & CNY \\
Investment in Real Estate & Real estate & 100 million \\
Development & Tourism & 100 million \\
Total Tourism Revenue & & CNY \\
Total Freight Traffic of Highways & Freight & 10,000 tons \\
Total Output of Grain Crops & Grain & 10,000 tons \\
\hline
\end{tabular}

\subsection{Data acquisition and pre-processing}

As GEE Landsat surface reflectance images were already atmospherically corrected (see section 2.2), the pre-processing involved masking clouds for all the imagery and stacking all imagery into one collection. Specifically, annual composites of the imagery were derived using the median operator and were then stacked into one collection in GEE to classify LULC. This workflow was carried out for each sensor.

The visible and near-infrared bands served directly as spectral features. We calculated the vegetation indices (NDVI, NDBI, MNDWI, SAVI, LSWI, EVI), and used NDVI to calculate second-order harmonic features to capture seasonal characteristics. We also used NDVI to calculate texture features. Lastly, JRC GSWM data, together with elevation and slope derived from SRTM data, served directly as features in the RF model. In total, 27 features were collected and calculated for the RF LULC classification model.

\subsection{Training data collection and classification}

We selected training samples using a stratified random sampling method based on classes in the reference map of 2017 obtained from FROM-GLC (Gong et al. 2019). The sample points collected for each class are listed in Table 3. We selected 200 sampling points for agricultural land, as it is a diverse class compared to the other vegetated LULC classes. More sampling points were selected for the impervious surface class (250), to allow for discrimination of three sub-classes (residential, industrial, and infrastructure) to more precisely identify the change processes within the class. Other LULC types were allocated based on the proportion of their areas in the reference map of 2017. In total, we collected 1100 samples for each year. At level 1, we defined a total of 8 LULC classes for this study, as shown in Table 3. The legend for the classes corresponds to the legend of FROM-GLC. We defined level 2 classification as an addition to the level 1 classification to provide more detailed sub-classes of the impervious surface class (see Table 3 ).

We collected the training data for the land cover classification by visually interpreting high-resolution imagery at the locations of the training sample points (see Zou (2020) for data access). Data collection was conducted using the "Collect," "Collect Earth" and "Google Earth Pro" software (see Figure 2), following 


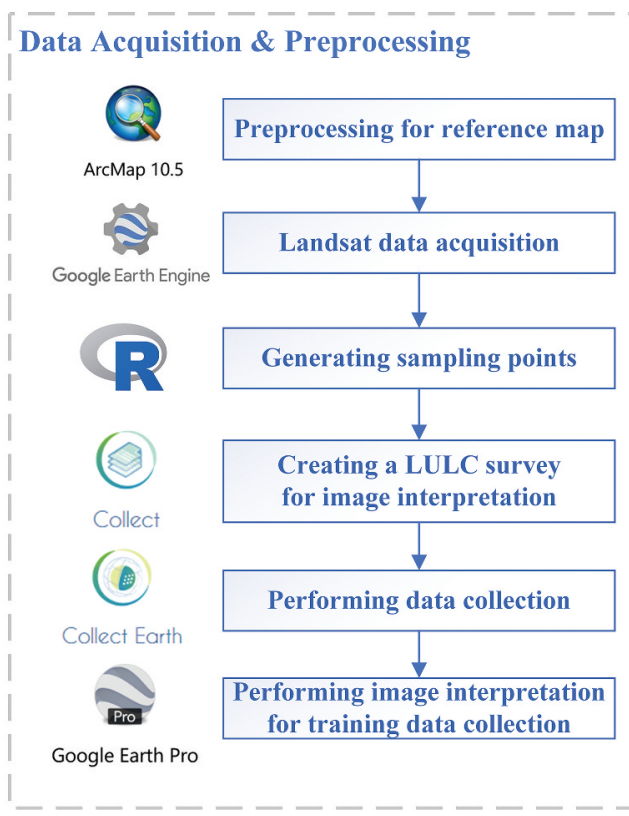

Figure 2. The overall workflow for this research.

the level 2 classification scheme as defined in Table 3. For each point, the LULC class was identified for each year in our study period, if high-resolution imagery was available.

Random forest (RF) nonparametric supervised classification algorithm (Breiman 2001) has been well established for land cover classification (Halmy et al. 2015; Colvocoresses 1981; Wu et al. 2013; Breiman 2001; Nguyen et al. 2020; Belgiu and Drăguț 2016; Tokar et al. 2018). We applied the RF algorithm using the function "ee.Classifier. RandomForest()" in GEE to classify LULC from Landsat time series imagery for each year from 2000 to 2017. Two models were trained, one for Landsat 5 and 7 (ETM+) data, and another for Landsat 8 (OLI) data, and each configured to grow 50 and 40 trees per class, respectively. This number was chosen after testing the model performance with different numbers of trees (from 10 to 50) per class. Lastly, we used the models to classify LULC for each year by using the features of the particular year (as listed in Table 1) as input.

In addition, we calculated the variable importance from RF in GEE to assess the contribution of each feature for improving the classifier performance. The detailed description for each variable can be found in Supplementary Table S1.

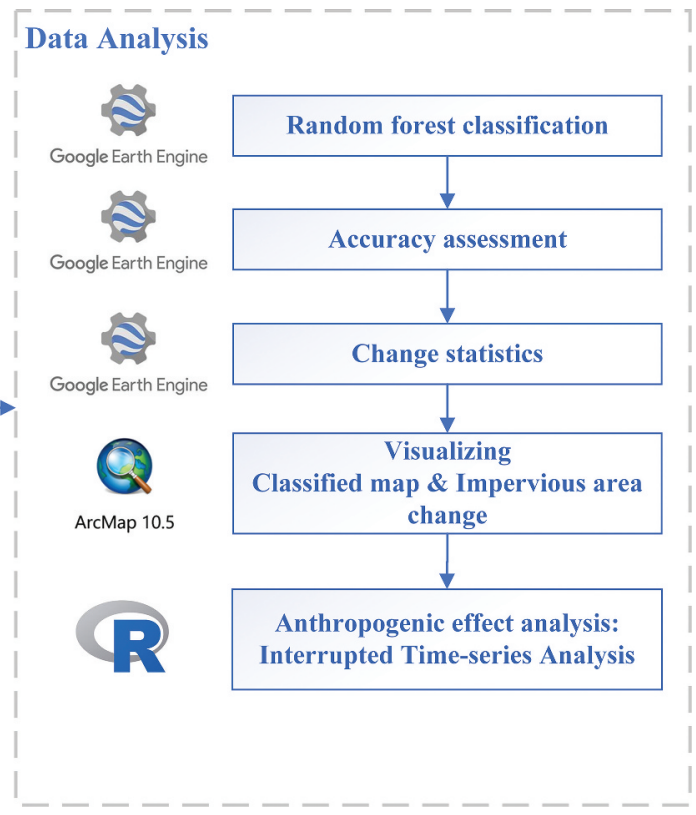

\subsection{Accuracy assessment and change statistics}

The accuracy of the resulting LULC maps was assessed in two ways: fivefold cross-validation using the collected training data, and an agreement comparison with the reference LULC maps. For each type of accuracy assessment, we created a confusion matrix, from which we calculated the overall accuracy, as well as users' and producers' accuracies for each class. After that, we used the LULC change (from-to) matrices between the first year of our analysis (2000), the year the bridge opened (2008), and the last year of our analysis (2017), to assess the land conversion processes.

We also used a confusion matrix to compare our classified maps with the reference maps. Unlike crossvalidation, in this case, the derived statistical metrics denote agreement, rather than accuracy, as the reference maps are also based on machine learning models, which makes it impossible to determine which of the models is closer to reality. The differences in the model outputs could also stem from the differences in the spatial extents of the models, the training data collection protocols, and the imagery used for both visual interpretation and classification. In addition, the classification legend (Table 3) was based on the legend of FROM-GLC, but it does not match the legend of GLC30. For instance, GLC30 defines mining and construction 
Table 3. Classification scheme and the numbers of sample points for each LULC class that was classified using the RF model.

\begin{tabular}{|c|c|c|c|}
\hline Level 1 & Level 2 & Number of sample points & Description \\
\hline 10 Agricultural land & & 200 & $\begin{array}{l}\text { Cultivated land, horticulture, and gardens, including paddy fields, irrigated } \\
\text { and dry farmland, vegetation, and fruit gardens, etc. }\end{array}$ \\
\hline 20 Forest & & 170 & $\begin{array}{l}\text { Trees higher than } 5 \mathrm{~m} \text {, including deciduous and coniferous forests, sparse } \\
\text { woodland, etc. }\end{array}$ \\
\hline 30 Grassland & & 130 & $\begin{array}{l}\text { Grass cover, including grasslands, meadows, fallow fields, and undeveloped } \\
\text { natural grasslands, etc. }\end{array}$ \\
\hline 40 Shrubland & & 100 & $\begin{array}{l}\text { Plant community characterized by shrubs, including small trees in the early } \\
\text { stage of growth. }\end{array}$ \\
\hline 50 Wetland & & 100 & $\begin{array}{l}\text { Land and water bodies covered with wetland plants, including inland } \\
\text { marsh, lake marsh, river floodplain wetland, forest/shrub wetland, peat } \\
\text { bogs, mangrove, and salt marsh, etc. }\end{array}$ \\
\hline 60 Water & & 100 & Open water: rivers, lakes, reservoirs, fishponds, and sea, etc. \\
\hline \multirow[t]{3}{*}{70 Impervious surface } & 71 Residential & 250 & $\begin{array}{l}\text { Built-up area in which housing predominates, as opposed to industrial and } \\
\text { commercial areas. }\end{array}$ \\
\hline & 72 Industrial & & Independently set up factories, workshops, handicraft workshops, etc. \\
\hline & 73 Infrastructure & & $\begin{array}{l}\text { All other impervious surface area excluding } 71 \text { and } 72 \text { : transportation } \\
\text { infrastructure, including roads and airports; construction infrastructure, } \\
\text { including building foundations; and facilities, such as engineering and } \\
\text { education facilities. }\end{array}$ \\
\hline 80 Bare land & & 50 & $\begin{array}{l}\text { Lands with vegetation cover lower than } 10 \% \text {, including desert, sandy fields, } \\
\text { bare rocks, saline and alkaline lands, etc. }\end{array}$ \\
\hline
\end{tabular}

areas to be part of the "artificial surface" class, whereas in FROM-GLC, these fall under "bare land." For this reason, when comparing our RF model output with GLC30 maps, the impervious surface and bare land classes were combined to facilitate a comparison against the artificial surface class of GLC30. Due to these mismatches between the models and the legends, we consider the cross-validation statistics to be a more reliable measure of our model accuracy than the reference map agreement statistics. Nevertheless, the reference map comparison is useful as a second, independent, source of information about the reliability of the RF model output.

Lastly, we assessed the change in area of each LULC class by performing a trend analysis using a simple linear regression between each LULC class and time. The linear regression was fitted for each LULC class for two time periods: before the opening of the bridge (2000-2008) and thereafter (2008-2017). The regression estimates a LULC change trend from the annual time series of LULC area. This trend is robust against individual outliers, therefore this method minimizes the effect of inter-annual variability. The sources of inter-annual variability could be physical differences, such as unusually dry or cold years, or differences between the classification model outputs caused by the RF method generating decision trees based on a random data subset. We chose this method because it is more robust compared to the common practice of taking a difference between two single-date maps, as any chosen single-date maps could be affected by inter-annual variability and lead to underestimation or overestimation of change.

\subsection{Application of ITSA on the time series of LULC and socio-economic indicators}

ITSA is the most commonly adopted method for quasiexperimental design to assess the impact of an intervention and it is applied in many disciplines, such as the economic, medical, and societal domains (Harris et al. 2006; Nistal-Nuño 2017; Penfold and Zhang 2013; Gillings, Makuc, and Siegel 1981; Jandoc et al. 2015). ITSA is a method used to measure intervention effects by comparing longitudinal trends before and after an intervention (Linden 2015; Penfold and Zhang 2013; Lopez Bernal et al. 2013). It performs a statistical evaluation of the impact of an intervention on the development of a variable over time. ITSA also provides the option to include a control group to compare the longitudinal trends before and after the interruption event between the intervention and the control group, which can help avoid false inference (Lopez Bernal et al. 2013; Linden 2015; Penfold and Zhang 2013). Although ITSA has been widely used in a variety of disciplines and was first introduced in the field of health services in 1981 (Gillings, Makuc, and Siegel 1981), it has never been used for LULC time series analysis before. If we consider the bridge construction as an intervention event in a longterm LULC time series, the change in LULC time series before and after the bridge construction is similar to, and can be analyzed as, an experiment for testing the 
influence of an intervention on a time series of a measured variable in the medical domain. Three prerequisites should be considered when implementing ITSA: a clear intervention event, a measurable variable and sequential data for the measured variable (Bernal, Cummins, and Gasparrini 2017). Our study meets all three prerequisites of ITSA, therefore, we used ITSA to investigate the LULC change in the context of the bridge construction. In this approach, the intervention effects were assessed by changes in the level and trend of the time series as well as the statistical significance of the intervention parameters. The control group is assumed to capture the change that would have happened even without the interruption. Thus, an effect is considered to be significant when the estimated post-interruption coefficients are significantly different from the ones predicted by taking into account their change in the control group. ITSA is implemented as a linear model with the following formula (for intervention status j, for group $k$, at time $\mathrm{t}$ ):

$$
\begin{aligned}
& \text { outcome }_{j k t}=\beta_{0}+\beta_{1} \times \text { time }_{t}+\beta_{2} \times \text { group }_{k}+\beta_{3} \times \\
& \text { group }_{k} \times \text { time }_{t}+\beta_{4} \times \text { level }_{j t}+\beta_{5} \times \text { trend }_{j t}+\beta_{6} \times \\
& \text { level }_{j t} \times \text { group }_{k}+\beta_{7} \times \text { trend }_{j t} \times \text { group }_{k}+\varepsilon_{j k t} .
\end{aligned}
$$

A detailed explanation of each coefficient is given in Table 4. ITSA was manually implemented in $\mathrm{R}$ and coupled with Autoregressive Moving Average (ARMA) models to adjust for autocorrelation effects.

We used ITSA to analyze the effects of the opening of the bridge on the change in impervious surface areas, including the level 2 subcategories, as well as on the change in the socio-economic indicators. The combined area of the two prefecture-level cities that are directly connected by the bridge (Jiaxing and Ningbo) was chosen as the intervention group, and Hangzhou was chosen as the control group, due to its greater distance from the bridge. In addition, to give more insight into the individual prefecture-level cities, we investigated their areas separately, although, considered separately, their areas are much smaller than that of Hangzhou. The interruption point was set to 2009 , as the bridge was opened to the public in late 2008.

\section{Results}

\subsection{LULC classification}

The annual LULC maps produced by the RF classifier

\begin{tabular}{|c|c|c|}
\hline Coefficient & Brief Name & Coefficient Explanation \\
\hline$\beta_{1}$ & $\begin{array}{l}\text { Pre-trend } \\
\text { (Control) }\end{array}$ & Trend before the interruption. \\
\hline$\beta_{2}$ & $\begin{array}{l}\text { Pre-level } \\
\text { difference } \\
\text { (intervention/ } \\
\text { control) }\end{array}$ & $\begin{array}{l}\text { Level difference between the } \\
\text { intervention and the control group at } \\
\text { the start of the study period. }\end{array}$ \\
\hline$\beta_{3}$ & $\begin{array}{l}\text { Pre-trend change } \\
\text { (intervention/ } \\
\text { control) }\end{array}$ & $\begin{array}{l}\text { Trend difference between the } \\
\text { intervention and control group during } \\
\text { the pre-interruption period. }\end{array}$ \\
\hline$\beta_{4}$ & $\begin{array}{l}\text { Post-level } \\
\text { difference } \\
\text { (control) }\end{array}$ & $\begin{array}{l}\text { Level change in the control group after } \\
\text { the interruption. }\end{array}$ \\
\hline$\beta_{5}$ & $\begin{array}{l}\text { Post-trend } \\
\text { difference } \\
\text { (control) }\end{array}$ & $\begin{array}{l}\text { Trend change in the control group after } \\
\text { the interruption. }\end{array}$ \\
\hline$\beta_{6}$ & $\begin{array}{l}\text { Post-level } \\
\text { difference } \\
\text { (intervention) }\end{array}$ & $\begin{array}{l}\text { Level difference after the interruption } \\
\text { between the intervention group and } \\
\text { the expected level when taking the } \\
\text { equivalent change in the control } \\
\text { group into account. }\end{array}$ \\
\hline$\beta_{7}$ & $\begin{array}{l}\text { Pre-post change in } \\
\text { trend difference } \\
\text { (intervention) }\end{array}$ & $\begin{array}{l}\text { Trend difference after the interruption } \\
\text { between the intervention group and } \\
\text { the expected trend when taking the } \\
\text { equivalent change in the control } \\
\text { group into account. }\end{array}$ \\
\hline$\varepsilon$ & Error term & It is the error terms in the ITSA model. \\
\hline
\end{tabular}
are the basis for all of the following analysis. The three
Table 4. Detailed explanation of each ITSA coefficient.

LULC maps, one for each of the key years of the analysis, namely 2000 (beginning of the study period), 2008 (opening of the Hangzhou Bay Bridge), and 2017 (end of the study period), are presented in Figure 3. The maps show that the dominant LULC type in the study area was forest, and that agricultural land was primarily located close to the sea, during the entire research period.

In the year 2000, residential areas occupied a relatively major fraction of the impervious surface areas, mainly within the city of Hangzhou. Leading up to the year 2008, there was a major expansion in industrial area and in wetlands. Industrial area replaced agricultural land, mainly in areas surrounding the residential areas of Hangzhou and Ningbo. This is consistent with a previous study in Hangzhou, which described the process of farmland conversion into peri-urban areas, which includes industrial development (Spiekermann et al. 2013). Additionally, wetland expanded along the shoreline of Ningbo and Jiaxing. Impervious surface areas continued to expand from 2008 to 2017, which indicates urbanization, particularly along the two banks of Hangzhou Bay. Infrastructure was the subclass of impervious surface areas that increased the most during this time. The LULC development of Ningbo from 2008 to 2017 differed from the other three prefecture-level 

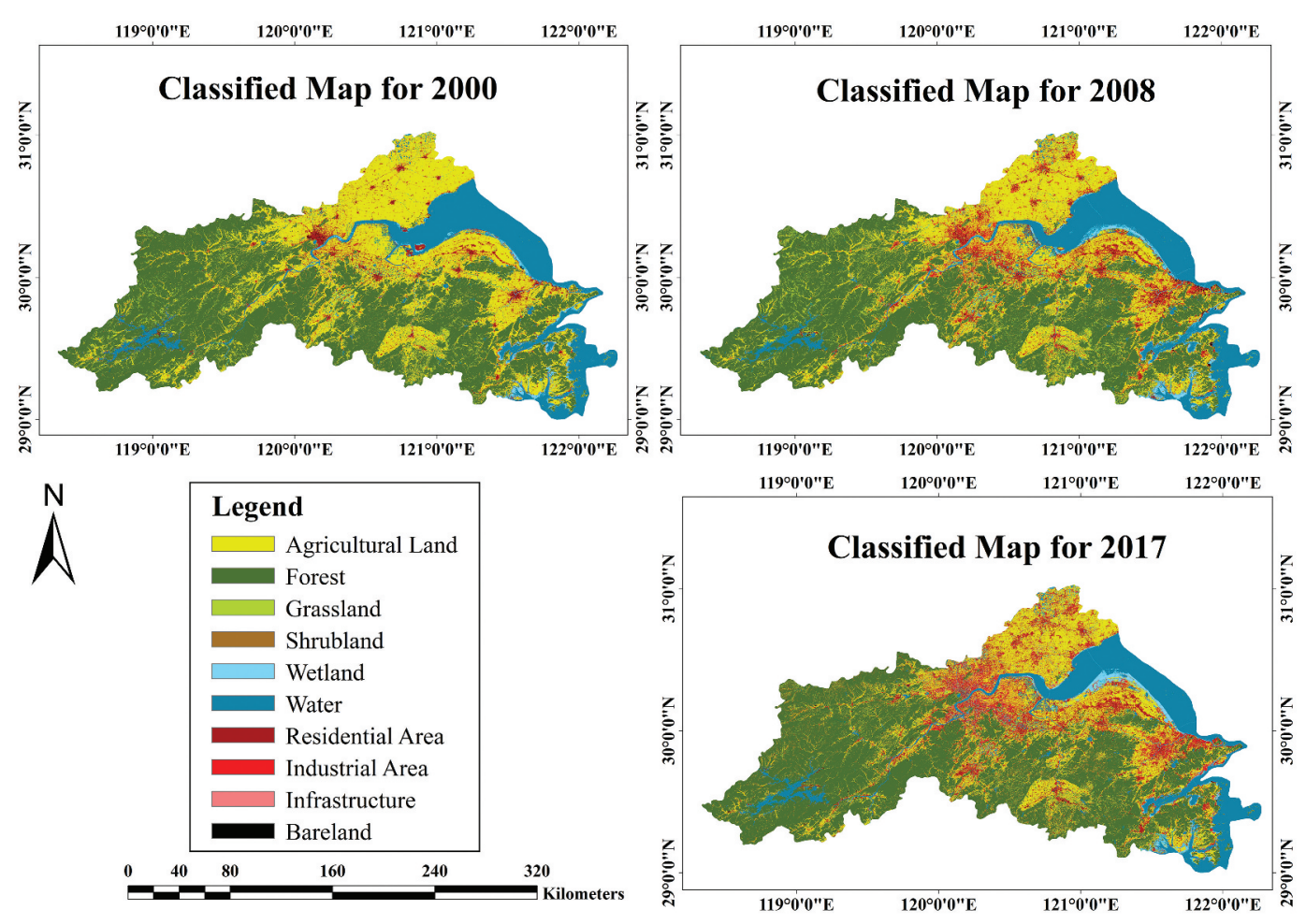

Figure 3. Maps of RF LULC classification for three years in the urban agglomeration of Hangzhou bay: the start of the study period (2000), the year when the bridge was opened for public use (2008), and the end of the study period (2017).

cities, as it showed less urbanization, but more agricultural land and wetland expansion, facilitated by the reclamation of land from the water.

\subsection{LULC accuracy assessment}

According to variable importance analysis, all features selected in this study contribute to the improvement of the RF model accuracy (Supplementary Figure S1). We calculated a confusion matrix from fivefold crossvalidation using the samples collected for this study. The overall accuracy of the RF model trained on Landsat 5 \& 7 (ETM+) data from 2000 to 2012 (85\%) was slightly better than the one trained on Landsat 8 (OLI) data from 2013 to 2017 (78\%) (Table 5). The User's Accuracy $\left(\mathrm{UA}_{1}\right)$ and Producer's Accuracy $\left(\mathrm{PA}_{1}\right)$ of agriculture, forest, water, and industrial land were above $70 \%$, which indicates that these classes are easier for the classifier to distinguish from the others. On the other hand, grassland, shrubland, infrastructure, and bare land had relatively lower $\mathrm{UA}_{1}$ and $\mathrm{PA}_{1}$ (less than 60\%) compared with the other classes. The models mostly confused vegetation classes with one another: grassland, shrubland, and forest (Supplementary Table S2). Infrastructure areas and bare land were also sometimes misclassified as agricultural, industrial, and residential land. For the years where Landsat 8 data were available and used for classification, the $\mathrm{PA}_{1}$ and $\mathrm{UA}_{1}$ of infrastructure areas and bare land improved by around $20 \%$, but the overall accuracy decreased (Table 5).

In addition to the cross-validation, we carried out an agreement comparison between the RF classified maps and the equivalent reference maps. The results are presented in Table 5 and Supplementary Tables S3 and S4. The overall agreement between RF outputs and both of the reference map sets (GLC30 and FROM-GLC) was $79 \%$. The producer's agreement and user's agreement of some of the classes, namely grassland, shrubland, wetland, and bare land, were less than $50 \%$, which is relatively lower compared with the other LULC classes. This is expected, as these classes are rare and more difficult to discern from one another. Moreover, the reference maps were also based on models, and thus errors from both models add up. For GLC30 agreement, another issue was the mismatch between the legends. Thus, it is expected that the agreement is much lower than the accuracy determined by cross-validation. In the following analysis, we focused only on the classes that 
Table 5. Model performance assessment result from fivefold cross-validation, as well as comparison with the reference maps in 2000, 2010, 2015, and 2017. For the comparison with GLC30, bare land and impervious surface areas were combined into the artificial surface category, and the result is presented in the column "Impervious surface" for those two years.

\begin{tabular}{|c|c|c|c|c|c|c|c|c|c|c|c|}
\hline \multicolumn{12}{|c|}{ 5-fold cross-validation } \\
\hline & Accuracy & Agriculture & Forest & Grass land & Shrub land & Wetland & Water & Residential & Industrial & Infrastructure & Bare land \\
\hline Landsat $5 \& 7$ & $\mathrm{PA}_{1}[\%]$ & 87 & 98 & 30 & 16 & 65 & 96 & 68 & 75 & 18 & 40 \\
\hline $\begin{array}{l}(2000-2012) \\
\mathrm{OA}_{1}=85 \%\end{array}$ & $\cup A_{1}[\%]$ & 79 & 94 & 37 & 34 & 80 & 94 & 60 & 77 & 41 & 54 \\
\hline Landsat 8 & $\mathrm{PA}_{1}[\%]$ & 86 & 94 & 43 & 58 & 76 & 92 & 71 & 74 & 36 & 68 \\
\hline $\begin{array}{l}(2013-2017) \\
\mathrm{OA}_{1}=78 \%\end{array}$ & $\mathrm{UA}_{1}[\%]$ & 78 & 91 & 56 & 62 & 82 & 92 & 64 & 74 & 51 & 69 \\
\hline \multicolumn{12}{|c|}{ Map Comparison } \\
\hline & Accuracy & Agriculture & Forest & $\begin{array}{l}\text { Grass } \\
\text { land }\end{array}$ & $\begin{array}{l}\text { Shrub } \\
\text { land }\end{array}$ & Wetland & Water & \multicolumn{3}{|c|}{ Impervious surface } & $\begin{array}{l}\text { Bare } \\
\text { land }\end{array}$ \\
\hline GLC30 & $\mathrm{PA}_{2}[\%]$ & 70 & 95 & 6 & 1 & 30 & 88 & \multicolumn{3}{|c|}{62} & - \\
\hline $\begin{array}{l}(2000,2010) \\
\mathrm{OA}_{2}=79 \%\end{array}$ & $\cup A_{2}[\%]$ & 84 & 81 & 18 & 1 & 13 & 93 & \multicolumn{3}{|c|}{53} & - \\
\hline FROM-GLC & $\mathrm{PA}_{2}[\%]$ & 78 & 89 & 6 & 22 & 30 & 84 & \multicolumn{3}{|c|}{$\begin{array}{l}74 \\
69\end{array}$} & 14 \\
\hline $\begin{array}{l}(2015,2017) \\
\mathrm{OA}_{2}=79 \%\end{array}$ & $\mathrm{UA}_{2}[\%]$ & 67 & 95 & 34 & 6 & 3 & 96 & \multicolumn{3}{|c|}{69} & 5 \\
\hline
\end{tabular}

can be discerned with higher accuracy, namely forest, agriculture, water, and impervious surface areas.

\subsection{LULC change statistics}

The LULC classes that had the most pronounced change in the study period were impervious land, forest, and agriculture (Figure 4). The area of forest (the most abundant class) fluctuated around $18,000 \mathrm{~km}^{2}$ throughout the study period. It decreased from 2000 until 2008, and then stayed around a constant level. Agricultural areas declined increasingly rapidly, from around $16,500 \mathrm{~km}^{2}$ in 2000 to less than $12,000 \mathrm{~km}^{2}$ in 2017 . The area of impervious surface increased from approximately $1,300 \mathrm{~km}^{2}$ in 2000 to $3,000 \mathrm{~km}^{2}$ in 2008 , and then further increased to more than $5,500 \mathrm{~km}^{2}$ in 2017 . The pace of change in impervious surface after bridge construction was therefore faster when compared to the period before. The majority of LULC changes occurred between these three classes. The potential reasons behind these LULC changes and a comparison with related previous studies can be found in the discussion section.

We observed several change processes when comparing the size of the area of each LULC class that changed into another class for the pre-bridge (2000-2008) and post-bridge (2008-2017) periods (see Figure 5 and Supplementary Table S5). The most striking change is urban expansion: impervious

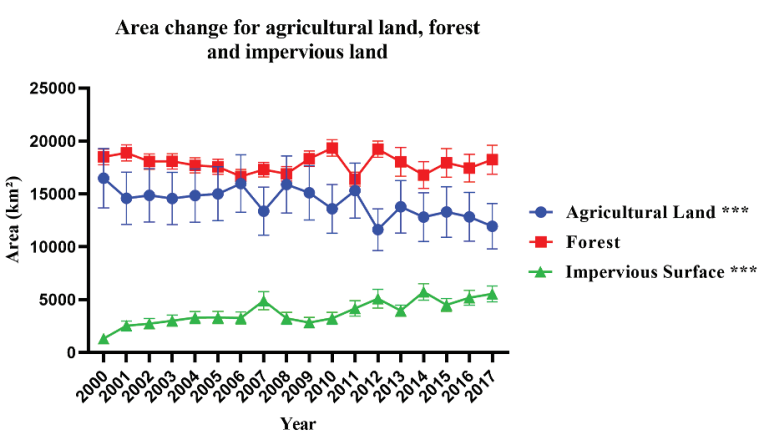

Figure 4. Area change for the main LULC classes from 2000 to 2017. The error bars represent the uncertainty of the area estimation for each year, based on the accuracy statistics from the 5 -fold cross-validation. The stars indicate that the trend of area change is significantly different from zero: ${ }^{*} p<0.05$; ${ }^{*}$ $\mathrm{p}<0.01$; ${ }^{* *} \mathrm{p}<0.001$.

surface was the fastest-growing class throughout the study period, with a growth rate of over $250 \mathrm{~km}^{2} /$ year. Urban areas primarily displaced agriculture, with over $2000 \mathrm{~km}^{2}$ replaced before the bridge opening, and over $2800 \mathrm{~km}^{2}$ replaced thereafter. Urban expansion also had a pronounced effect on the area occupied by smaller classes such as wetlands and water. Eight percent $\left(59 \mathrm{~km}^{2}\right)$ of the wetlands in the study area were turned into impervious surface areas in the pre-bridge period, and a further $16 \%\left(153 \mathrm{~km}^{2}\right)$ in the post-bridge period. Similarly, $56 \mathrm{~km}^{2}$ of water were turned into impervious land in the pre-bridge and $98 \mathrm{~km}^{2}$ in the post-bridge period. This shows that land reclamation from water took place, in part to 


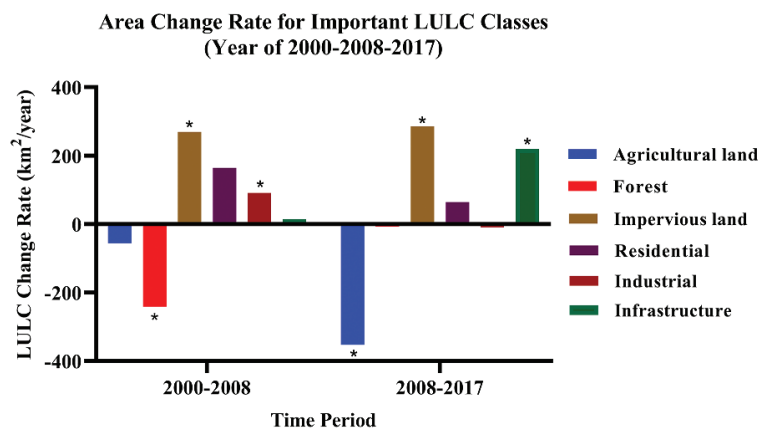

Figure 5. Area change rate plot for the main LULC types: Agriculture, forest, impervious land, residential, industrial, and infrastructure. The stars indicate that the trend is significantly different from zero ( $p$-value $\leq 0.05$ ). See Supplementary Table S5 for the full table of LULC class transitions.

support urban expansion. The effect of the opening of the bridge can be seen in the change in the type of impervious surface that drives urban expansion: the pre-bridge period is dominated by industrial area expansion (91 km²/year), whereas the post-bridge period is dominated by infrastructure area expansion (220 $\mathrm{km}^{2} /$ year).

Water was reclaimed not only for impervious land but also for agricultural areas $\left(94 \mathrm{~km}^{2}\right.$ during the pre-bridge period, $110 \mathrm{~km}^{2}$ in the post-bridge period). This land reclamation was most prominent around the shoreline of Ningbo, and it has been noted in a previous study on Hangzhou Bay (Chu et al. 2020). In addition, a large area of water changed into wetland $\left(380 \mathrm{~km}^{2}\right.$ pre-bridge, $439 \mathrm{~km}^{2}$ post-bridge), of which some also changed back into water $\left(203 \mathrm{~km}^{2}\right.$ pre-bridge, $207 \mathrm{~km}^{2}$ post-bridge).

Forest area declined rapidly (over $200 \mathrm{~km}^{2} /$ year) in the pre-bridge period, whereas in the post-bridge period it remained around an overall constant level (see Figure 5). The conversion from forest to agricultural areas in the post-bridge period $\left(555 \mathrm{~km}^{2}\right)$ was less than one-third of that in the pre-bridge period $\left(1875 \mathrm{~km}^{2}\right)$, and, simultaneously, the conversion from agricultural areas to forest increased from $435 \mathrm{~km}^{2}$ during the pre-bridge period to $2318 \mathrm{~km}^{2}$ in the postbridge period. As a result, agricultural areas declined both due to conversion to forest and to impervious land in the post-bridge period, but to partially compensate for the loss in area, it expanded into the land reclaimed from water.

\subsection{The influence of the bridge construction on LULC and socio-economic indicators}

\subsubsection{Bridge construction effects on impervious surface area change}

To determine the effect of the opening of the Hangzhou Bay Bridge on the change in LULC class areas, we applied the ITSA method on the impervious land class and its sub-classes in the joint NingboJiaxing area and used the Hangzhou area as the control group (Figure 6 and Supplementary Table S6). We also included the separate Ningbo and Jiaxing areas for comparison purposes. The results for impervious surface areas as a whole showed a significant trend of increasing urban expansion after the opening of the bridge in the joint Jiaxing-Ningbo area $\left(+41 \mathrm{~km}^{2} /\right.$ year compared to the estimated value based on the Hangzhou trend change). Looking at the areas separately, Jiaxing alone also showed a higher trend for impervious land expansion $\left(+17 \mathrm{~km}^{2} /\right.$ year $)$. The increased expansion is due to the bridge, which stimulated city development and thus promoted local construction of infrastructure and industry.

Regarding changes in the residential area, there was little change (less than $+45 \mathrm{~km}^{2} /$ year) between the prebridge period and the post-bridge period for all areas except the control group of Hangzhou, which had rapid urbanization in the pre-bridge period that stalled in the post-bridge period. The change in the industrial areas showed a very different picture, with rapid industrialization taking place in the pre-bridge period in all areas and stalling in the post-bridge period. This effect was especially pronounced in the Jiaxing-Ningbo and Ningbo areas, which had a rapid increase in industrial areas until the bridge opening, and almost no further increase since then. This effect was less pronounced in Jiaxing, which did not have such rapid industrialization before the opening of the bridge.

The most prominent change after the opening of the bridge was in the infrastructure areas, which include roads and building foundations. While the growth in infrastructure was limited in the pre-bridge period, it experienced a boom throughout all the areas during the post-bridge period. The area of the bridgeconnected cities showed a significantly faster increase in infrastructure area compared to Hangzhou. A detailed explanation for each coefficient can be found in Table 4, and the detailed information 

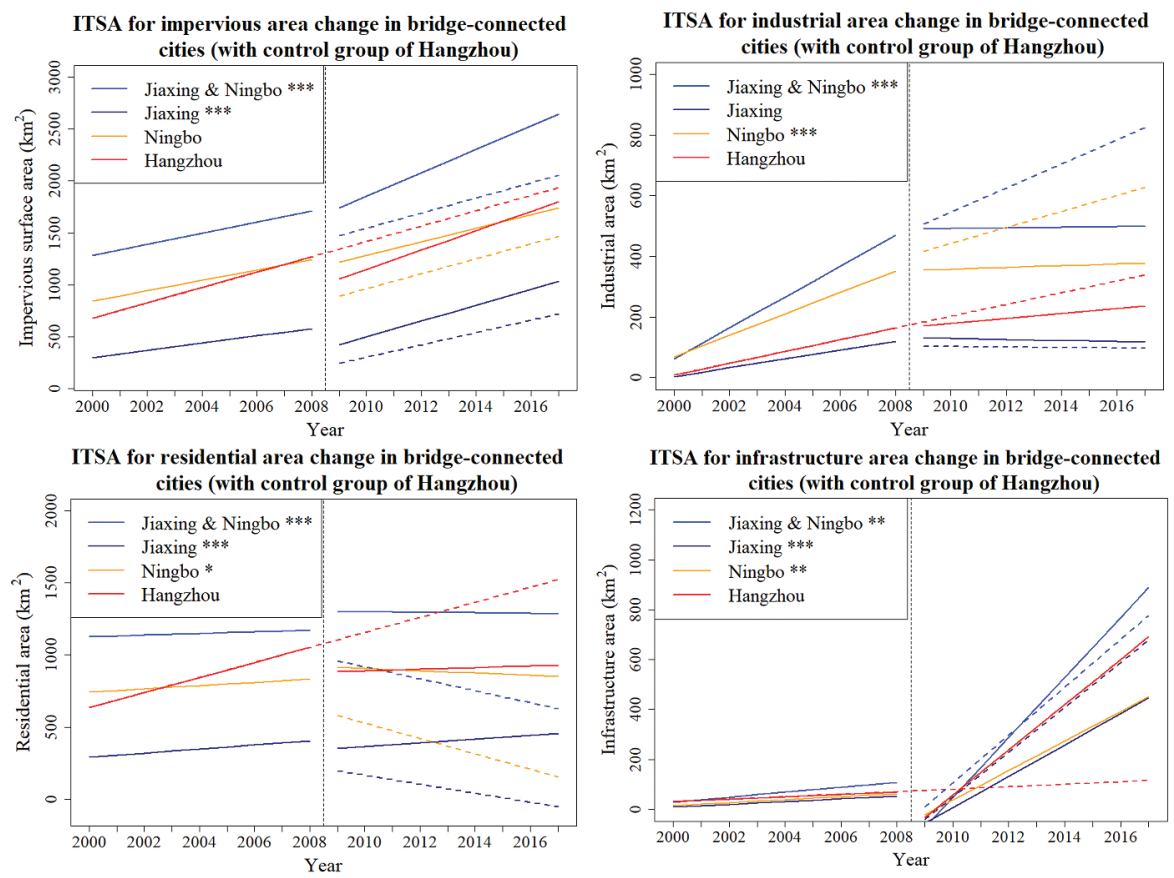

Figure 6. ITSA plots for the change in impervious land and its sub-classes in the bridge-connected prefecture-level cities, with the more distant Hangzhou serving as a control group. The stars in the legend indicate the statistical significance of post-interruption trend (solid lines) difference from the predictions (dashed lines) based on change observed in the control group: ${ }^{*} \mathrm{p}<0.05 ;{ }^{* *}$ $\mathrm{p}<0.01$; $^{* *} \mathrm{p}<0.001$.

regarding ITSA statistic results can be found in Supplementary Table S6.

\subsubsection{Bridge construction effect on socio-economic indicator change}

Some significant results of ITSA when applied on socio-economic indicators in the combined JiaxingNingbo area are presented in Figure 7, and the remaining factors are presented in Supplementary Figure S2. There was a remarkable increase in the trend of GDP, freight, fixed assets, tertiary industry, and tourism after the bridge opening in 2009. This shows that the bridge connection facilitated the accessibility of transportation, thus promoting various aspects of economic development. Aside from being convenient for tourists, the sea-cross bridge itself has become a tourist attraction, stimulating local tourism. However, tourism revenue increased exponentially over the course of the study period, showing that the tourism market adapts to the new developments gradually over time. Moreover, the bridge saves time and cost of transportation, thus directly increasing freight traffic and indirectly stimulating investments in fixed assets (e.g. cars and trucks); all these effects boost local GDP.

\section{Discussion}

\subsection{Comparison with previous studies}

The aim of this study was to assess the spatial and temporal impact of the Hangzhou Bay Bridge on the time series of LULC and socio-economic indicators in four prefecture-level cities in eastern China. Our findings on the rate of impervious surface expansion and socio-economic factors agree with a previous study at the local level of Cixi county of Ningbo, which showed a substantial increase in urban area and GDP during the study period (Shahtahmassebi et al. 2018). Another study concerning Cixi county also indicated a rising urbanization trend, as well as an increase in GDP and freight traffic in the period leading up to the opening of the bridge (Zheng et al. 2016), which is consistent with our findings at the regional level as well. However, our study has a broader context in both space and time and thus expands on these studies to show that the impervious land 
ITSA for Tertiary Industry in Ningbo \& Jiaxing

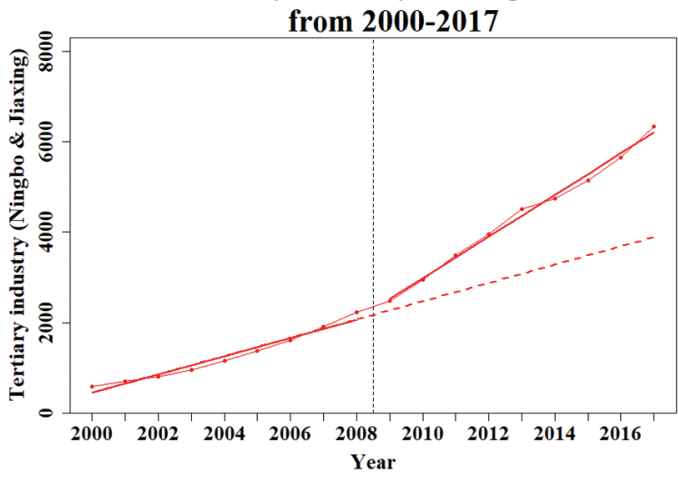

ITSA for Fixed Assets in Ningbo \& Jiaxing from 2000-2017

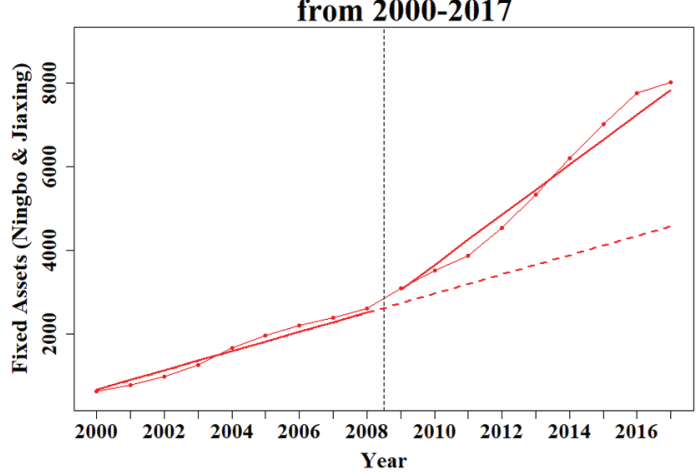

ITSA for Freight in Ningbo \& Jiaxing from 2000-2017

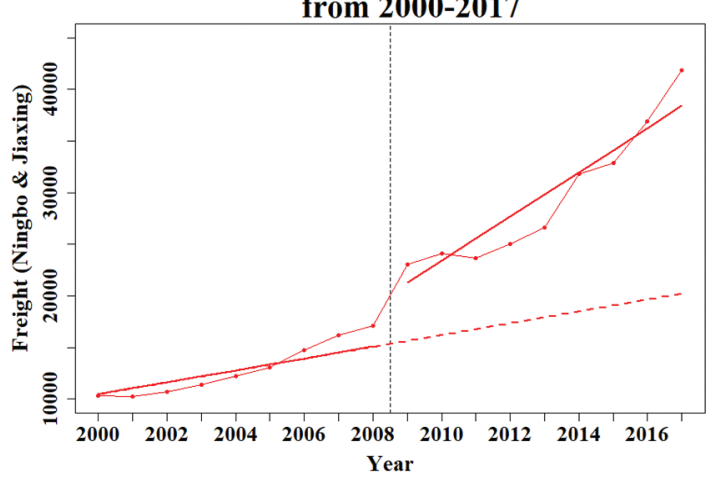

ITSA for GDP in Ningbo \& Jiaxing from 2000-2017

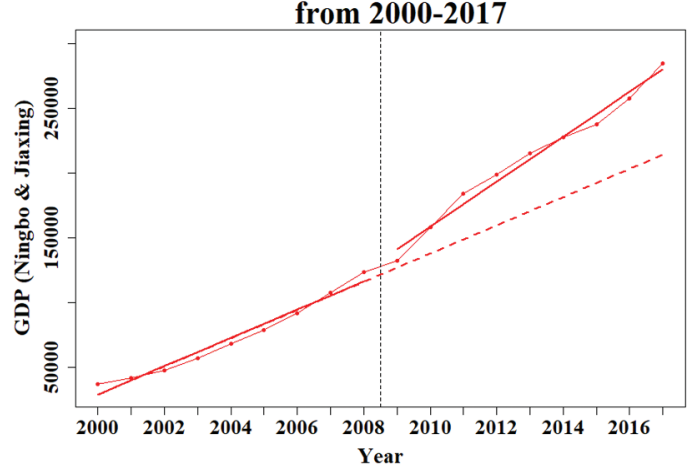

ITSA for Tourism in Ningbo \& Jiaxing from 2000-2017
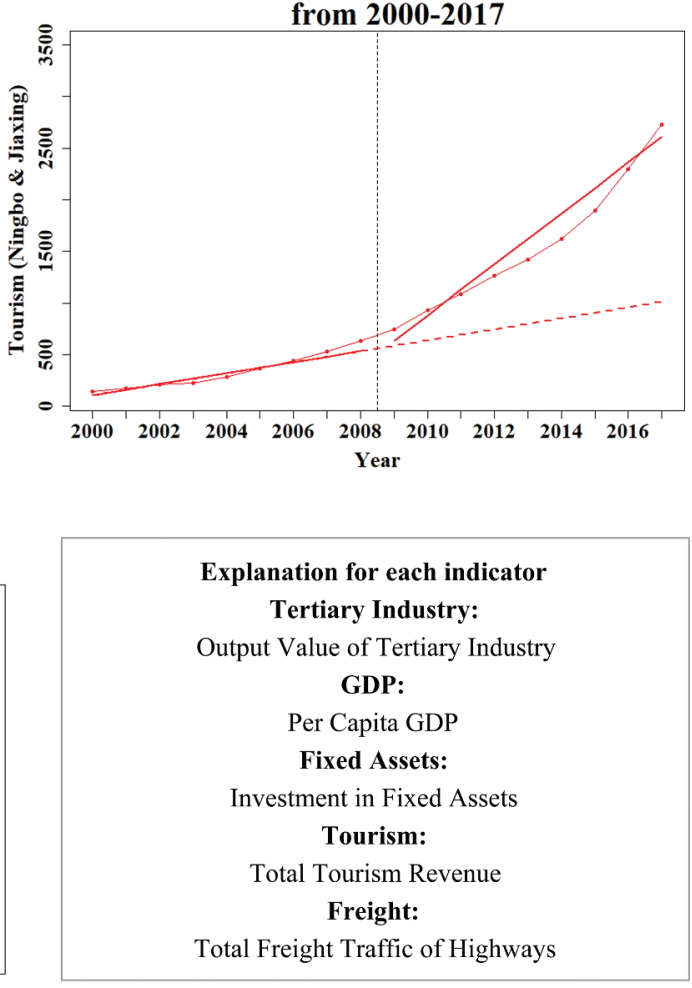

Legend

$\rightarrow$ Original time series - Trendline with intervention $\quad--$ Trendline without intervention

Figure 7. ITSA applied on social-economic indicators of the joint areas of Jiaxing and Ningbo. All the indicators shown here have a statistically significant increase in trend after the bridge opening. The detailed statistical results can be found in Supplementary Table S7.

expansion accelerated faster after the bridge was open for public use. In addition, while the previous studies attributed the changes to the construction of the bridge, they did not take into account the possibility that the changes would also have occurred without the construction of the bridge. The combination of a larger temporal and spatial extent and the use of a control group in ITSA enabled us to avoid such false inference in our study. Based on the comparison with Hangzhou, our results suggest that the urban expansion would have taken place even without the construction of the bridge, especially in the time before the bridge was operational. 


\subsection{Findings from the classification results and methods}

Most of the previous studies in and around our research area focused on the impervious land and urban intensification when investigating LULC change, while the results of our study showed more detailed LULC class conversion processes for the pre- and the post-bridge construction periods. The collection of more detailed LULC training data made it possible to discern sub-classes of the impervious surface class, giving further insight into the urban expansion process. It showed that the bridge spurred the development of infrastructure, such as roads, rather than industry or residential buildings. In addition, our results showed that following a decrease during the pre-bridge period, the forest area became stable, which may be due to a new sustainable development policy that was introduced in the area (Zheng et al. 2016). This improvement in the forest change trend provides new evidence of the effectiveness of the new policy on sustainable development of ground transportation infrastructure, such as bridge constructions.

\subsection{Findings from applying ITSA on the LULC and socio-economic indicator time series}

To our knowledge, no prior studies have applied ITSA on LULC time series to assess the LULC changes influenced by an intervention event. We applied this method to compare the longitudinal trends before and after the bridge construction between the intervention group and the control group, and the results highlight the influence of the bridge construction on the LULC and socio-economic indicator time series. Through the comparison of the predicted changes and the post-intervention changes for the detailed LULC classes, including impervious surface subclasses, the positive and negative influences of the bridge construction on LULC dynamics can be assessed. This information can be used by policymakers to make decisions that help local urban development become more sustainable.

Applying ITSA on the LULC time series showed that impervious land expanded increasingly rapidly after the opening of the bridge in the cities it connects, compared to cities further away from the bridge. This shows that the bridge further accelerated the process of urban expansion. Within the impervious land class, the infrastructure area expanded significantly in the post-bridge-opening period, compared with the prebridge period. Furthermore, ITSA results on socioeconomic indicators showed that except for the consistently increasing registered population indicator and the declining grain production indicator, almost all socio-economic indicators, especially for the GDP, highway traffic freight, tertiary industry, tourism revenue, and investments in fixed assets, increased more rapidly after the construction of the bridge (Figure 7 and Supplementary Table S7). These findings indicate that the Hangzhou Bay Bridge further accelerated urban sprawl and almost every considered aspect of socio-economic development. Our study complements the conclusions of previous studies, in which the substantial increases in urbanization, GDP, and freight traffic after the opening of the bridge were reported (Shahtahmassebi et al. 2018; Zheng et al. 2016). This shows that a combination of ITSA and LULC classification using machine learning is a comprehensive and transferrable method to assess the influence of notable events on LULC change. Methods from this study could contribute to the monitoring of LULC dynamics, socioeconomic indicator changes, and even the ecological and anthropogenic environments to support regional sustainable development policymaking.

\subsection{Limitations and recommendations for future research}

To obtain reliable LULC change, ideally, the data used as input to the classifier should be as reliable as possible. One limitation of the input data is the lack of SLC-on data for 2012. We mitigated this limitation by using annual median composites of all available images for any given year. Nevertheless, the values for 2012 may be less reliable, but we expect that this did not significantly affect the trend analysis results, as they are based on multi-year trends and not on any year in particular.

Another source of error are the models themselves. As the output from machine learning algorithms, such as random forest, is not perfect and has associated errors, deriving change based on subsequent annual maps is prone to overestimating changes merely due to small fluctuations in the input data. We mitigated this problem in this study by analyzing long-term trends of LULC change in the time series, rather than looking only at individual time points. This could be further improved by adopting other models for break detection or post-processing, like the Hidden Markov 
Model (Siachalou, Mallinis, and Tsakiri-Strati. 2015; Kligys and Rozovskii 1998), which would help to further reduce spurious change from the output maps. Another limitation of machine learning models is that a small sample size for some rare and difficult to distinguish LULC types, like shrubland, grassland, infrastructure area, and bare land, can lead to lower accuracies for those classes, as the models are dataintensive (Millard and Richardson 2015). Using additional sources of high-resolution imagery and field data and increasing the training sample size for some LULC types could improve the classification accuracy.

The bridge construction, LULC change, and socioeconomic indicator change are all interlinked and interacting with one another, making it difficult to separate cause from effect (e.g. bridge promotes tourism, but tourism promotes bridges). Such a complex system has confounding drivers, indirect effects, and feedbacks, which limit the ability of researchers to explain the drivers of the influence of such an interruption event. ITSA enables us to narrow down the potential effects and gain more insight into the mechanism that drives them, albeit it does not cover all the possibilities.

One limitation of using ITSA with a control group is that the control group is assumed to be completely representative of the change without the interruption effect. However, in LULC research, such a perfect control group is unlikely to be available. The differences between the control and intervention groups may, therefore, result in unusual patterns of modeled expected change of the intervention group after the interruption. Another limitation related to ITSA is the potential confounding effect of a competing intervention. In this study period, a new, smaller bridge (Jiaxing-Shaoxing bridge) in Hangzhou Bay was opened in 2013. Unfortunately, we could not assess the impact of the Jiaxing-Shaoxing bridge, as only 4 years of data were available since then, which is not enough for a robust comparison and estimation of trends before and after the opening of the new bridge. Thus, some of the changes that our study attributes to the Hangzhou Bay Bridge may instead be attributed to this new bridge. In follow-up studies where such data would be available, we recommend using a longer time series, multiple intervention points, and an additive modeling approach to disentangle the effects of such interventions.
Also, a potential direction for further research into this topic would be to compare our empirical results in that of a simulation model, such as the Land Change Modeler (LCM) (Jain, Jain, and Rehan Ali 2017) and CLUE-S model (Verburg et al. 2002). This could provide further insights into the intervention effect on LULC change by simulating the evolution based on different scenarios (with/without interventions) and considering comprehensive driving factors for LULC change.

\section{Conclusion}

In this study, we identified and quantified 18 years of LULC change in the Hangzhou Bay agglomeration using a machine learning classifier. We quantified the LULC conversion trends throughout the study period and focused on the construction of the Hangzhou Bay Bridge. In addition, we demonstrated a novel application of the ITSA method on the LULC time series, and the results provided a comprehensive statistical assessment of the influence of the bridge opening on the change in both LULC and socioeconomic indicators. The output of this work furthers our understanding of the role of major infrastructure development, in this case bridge construction, on the development of the urban agglomeration by assessing the influence of ground transportation infrastructure on the urban environment and socio-economic factors. The methods in this study contribute to evidence-based urban management plans and realistic policies for sustainable management of urban ecosystems. The methods adopted in this study can be transferred to assess the effect of any notable event that may affect LULC change and socio-economic indicators in any area.

\section{Acknowledgements}

We thank Aidas Masiliūnas for the initial idea of applying ITSA to this research. We thank Francis Oloo for the proofreading of the manuscript. We gratefully acknowledge constructive remarks by editors and anonymous reviewers.

\section{Author Contributions}

Lixia Chu: conceptualization, supervision, writing - original draft, writing - review \& editing. Yuting Zou: software, validation, formal analysis, data curation, writing - original draft. 
Dainius Masiliūnas: conceptualization, methodology, writing original draft, writing - review \& editing. Thomas Blaschke: supervision, funding acquisition, writing - review \& editing. Jan Verbesselt: supervision, project administration, methodology, writing - review \& editing.

\section{Data and Code Availability Statement}

The training dataset for random forest classification and the code created for this study are openly available in zenodo, at http://doi.org/10.5281/zenodo.3960517 and http://doi.org/10. 5281/zenodo.3959969 respectively.

\section{Disclosure statement}

No potential conflict of interest was reported by the authors.

\section{Funding}

The work is partially funded by the Austrian Science Fund [DK W1237-N23].

\section{ORCID}

Lixia Chu (iD http://orcid.org/0000-0003-3834-3394

Yuting Zou (D) http://orcid.org/0000-0002-5487-1253

Dainius Masiliūnas (ID) http://orcid.org/0000-0001-5654-1277

Thomas Blaschke (D) http://orcid.org/0000-0002-1860-8458

Jan Verbesselt (iD http://orcid.org/0000-0001-7923-4309

\section{References}

Aa, K. M., and J. Rich. 2013. "Ex Post Socio-economic Assessment of the Oresund Bridge." Transport Policy 27: 53-65. doi:10.1016/j.tranpol.2012.12.002.

Belgiu, M., and L. Drăguț. 2016. "Random Forest in Remote Sensing: A Review of Applications and Future Directions." ISPRS Journal of Photogrammetry and Remote Sensing 114: 24-31. doi:10.1016/j.isprsjprs.2016.01.011.

Bernal, J. L., S. Cummins, and A. Gasparrini. 2017. “Interrupted Time Series Regression for the Evaluation of Public Health Interventions: A Tutorial." International Journal of Epidemiology 46 (1): 348-355. doi:10.1093/ije/dyw098.

Bernal, L., A. James, C. M. A. Antonio Gasparrini, and M. Martin. 2013. "The Effect of the Late 2000s Financial Crisis on Suicides in Spain: An Interrupted Time-series Analysis." European Journal of Public Health 23 (5): 732-736. doi:10.1093/eurpub/ckt083.

Breiman, L. 2001. "Random Forests." Machine Learning 45 (1): 5-32. doi:10.1023/A:1010933404324.

Cai, X., W. Zhifeng, and J. Cheng. 2013. “Using Kernel Density Estimation to Assess the Spatial Pattern of Road Density and Its Impact on Landscape Fragmentation." International
Journal of Geographical Information Science 27 (2): 222-230. doi:10.1080/13658816.2012.663918.

Chandrasekar, K., M. V. R. Sesha Sai, P. S. Roy, and R. S. Dwevedi. 2010. "Land Surface Water Index (LSWI) Response to Rainfall and NDVI Using the MODIS Vegetation Index Product." International Journal of Remote Sensing 31 (15): 3987-4005. doi:10.1080/01431160802575653.

Chen, J., J. Chen, A. Liao, X. Cao, L. Chen, X. Chen, H. Chaoying, et al. 2015. "Global Land Cover Mapping at 30m Resolution: A POK-based Operational Approach." ISPRS Journal of Photogrammetry and Remote Sensing 103: 7-27. doi:10.1016/j.isprsjprs.2014.09.002.

Chen, S.-S., L.-F. Chen, Q.-H. Liu, L. Xia, and Q. Tan. 2005. "Remote Sensing and GIS-based Integrated Analysis of Coastal Changes and Their Environmental Impacts in Lingding Bay, Pearl River Estuary, South China." Ocean \& Coastal Management 48 (1): 65-83. doi:10.1016/j. ocecoaman.2004.11.004.

Chu, L., F. Oloo, M. Sudmanns, D. Tiede, D. Hölbling, T. Blaschke, and I. Teleoaca. 2020. "Monitoring Long-term Shoreline Dynamics and Human Activities in the Hangzhou Bay, China, Combining Daytime and Nighttime EO Data." Big Earth Data 1-23. doi:10.1080/20964471.2020.1740491.

Colvocoresses, A. P. 1981. "Digital Elevation Data as an Aid to Land Use and Land Cover Classification." In Pecora VII Symposium 92-93. https://pubs.er.usgs.gov/publication/70113017.

Cui, L., G. Zhenming, L. Yuan, and L. Zhang. 2015. "Vulnerability Assessment of the Coastal Wetlands in the Yangtze Estuary, China to Sea-level Rise." Estuarine, Coastal and Shelf Science 156: 42-51. doi:10.1016/j.ecss.2014.06.015.

Disperati, L., and P. V. Salvatore Gonario. 2015. "Assessment of Land-use and Land-cover Changes from 1965 to 2014 in Tam Giang-Cau Hai Lagoon, Central Vietnam." Applied Geography 58: 48-64. doi:10.1016/j. apgeog.2014.12.012.

Feng, F., J. Wang, Z. Ke, Z. Yuan, S. Qiang, F. Tengao, W. Meifu, et al. 2017. "Zhejiang Statistics Yearbook 2017." [Dataset]. Zhejiang Provincial Bureau of Statistics. https://zjjcmspublic. oss-cn-hangzhou-zwynet-d01-a.internet.cloud.zj.gov.cn/ jcms_files/jcms1/web3077/site/flash/tjj/Reports 1/2017\% E7\%BB\%9F\%E8\%AE\%A 1\%E5\%B9\%B4\%E9\%89\%B4\%E5\% 85\%89\%E7\%9B\%98\%E6\%94\%B9\%E5\%90\%8E20190415/ indexeh.htm

Gillings, D., D. Makuc, and E. Siegel. 1981. "Analysis of Interrupted Time Series Mortality Trends: An Example to Evaluate Regionalized Perinatal Care." American Journal of Public Health 71 (1): 38-46. doi:10.2105/AJPH.71.1.38.

Gong, P., H. Liu, M. Zhang, L. Congcong, J. Wang, H. Huang, N. Clinton, et al. 2019. "Stable Classification with Limited Sample: Transferring a 30-m Resolution Sample Set Collected in 2015 to Mapping 10-m Resolution Global Land Cover in 2017." Science Bulletin 64 (6): 370-373. doi:10.1016/ j.scib.2019.03.002.

Gorelick, N., M. Hancher, M. Dixon, S. Ilyushchenko, D. Thau, and R. Moore. 2017. "Google Earth Engine: Planetary-scale Geospatial Analysis for Everyone." Remote Sensing of Environment 202: 18-27. doi:10.1016/j.rse.2017.06.031. 
Guo, Y., X. Zhang, T. Long, W. Jiao, H. Guojin, R. Yin, and Y. Dong. 2020. "China Forest Cover Extraction Based on Google Earth Engine." The International Archives of Photogrammetry, Remote Sensing and Spatial Information Sciences 42: 855-862. doi:10.5194/isprs-archives-XLII -3-W10-855-2020.

Hagenaars, G., A. Luijendijk, S. de Vries, and D. B. Wiebe. 2017. "Long Term Coastline Monitoring Derived from Satellite Imagery." In Proceedings of Coastal Dynamics 2017, 15511562. Helsingør, Denmark.

Halmy, M., A. Waseem, P. E. Gessler, J. A. Hicke, and B. B. Salem. 2015. "Land Use/land Cover Change Detection and Prediction in the North-western Coastal Desert of Egypt Using Markov-CA." Applied Geography 63: 101-112. doi:10.1016/j.apgeog.2015.06.015.

Halpern, B. S., S. Walbridge, K. A. Selkoe, C. V. Kappel, F. Micheli, C. D'agrosa, J. F. Bruno, K. S. Casey, C. Ebert, and H. E. Fox. 2008. "A Global Map of Human Impact on Marine Ecosystems." Science 319 (5865): 948-952. doi:10.1126/ science. 1149345.

Harris, A. D., J. C. McGregor, E. N. Perencevich, J. P. Furuno, J. Zhu, D. E. Peterson, and J. Finkelstein. 2006. "The Use and Interpretation of Quasi-experimental Studies in Medical Informatics." Journal of the American Medical Informatics Association 13 (1): 16-23. doi:10.1197/jamia.M1749.

Huete, A. R. 1988. "A Soil-adjusted Vegetation Index (SAVI)." Remote Sensing of Environment 25 (3): 295-309. doi:10.1016/ 0034-4257(88)90106-X.

Jain, R. K., K. Jain, and S. Rehan Ali. 2017. "Modeling Urban Land Cover Growth Dynamics Based on Land Change Modeler (LCM) Using Remote Sensing: A Case Study of Gurgaon, India." Advances in Computational Sciences and Technology 10 (10): 2947-2961.

Jandoc, R., A. M. Burden, M. Mamdani, L. E. Lévesque, and S. M. Cadarette. 2015. “Interrupted Time Series Analysis in Drug Utilization Research Is Increasing: Systematic Review and Recommendations." Journal of Clinical Epidemiology 68 (8): 950-956. doi:10.1016/j. jclinepi.2014.12.018.

Kligys, S., and B. L. Rozovskii. 1998. "State Estimation in Hidden Markov Models with Distributed Observation." In Theory and Practice of Control and Systems, 328-330. Alghero, Sardinia, Italy.

Lein, J. K., and K. L. Day. 2008. "Assessing the Growth-inducing Impact of the Appalachian Development Highway System in Southern Ohio: Did Policy Promote Change?" Land Use Policy 25 (4): 523-532. doi:10.1016/j.landusepol.2007.11.006.

Lin, G. C. S. 1999. "Transportation and Metropolitan Development in China's Pearl River Delta: The Experience of Panyu." Habitat International 23 (2): 249-270. doi:10.1016/ S0197-3975(98)00049-6.

Linden, A. 2015. "Conducting Interrupted Time-series Analysis for Single- and Multiple-group Comparisons." The Stata Journal 15 (2): 480-500. doi:10.1177/ $1536867 X 1501500208$.

Liu, H. Q., and A. Huete. 1995. "A Feedback Based Modification of the NDVI to Minimize Canopy Background and Atmospheric
Noise." IEEE Transactions on Geoscience and Remote Sensing 33 (2): 457-465. doi:10.1109/TGRS.1995.8746027.

Long, H., G. Tang, L. Xiubin, and G. K. Heilig. 2007. "Socioeconomic Driving Forces of Land-use Change in Kunshan, the Yangtze River Delta Economic Area of China." Journal of Environmental Management 83 (3): 351-364. doi:10.1016/j. jenvman.2006.04.003.

Masek, J. G., E. F. Vermote, N. E. Saleous, R. Wolfe, F. G. Hall, K. F. Huemmrich, F. Gao, J. Kutler, and T.-K. Lim. 2006. "A Landsat Surface Reflectance Dataset for North America, 1990-2000." IEEE Geoscience and Remote Sensing Letters 3 (1): 68-72. doi:10.1109/LGRS.2005.857030.

McLean, R. F., A. Tsyban, V. Burkett, J. O. Codignotto, D. L. Forbes, N. Mimura, R. J. Beamish, and V. Ittekkot. 2001. "Coastal Zones and Marine Ecosystems." In Climate Change 2001: Impacts, Adaptation and Vulnerability, edited by J. J. McCarthy, O. F. Canziani, N. A. Leary, D. J. Dokken, and K. S. White, 343-379. Cambridge: Cambridge University Press.

Millard, K., and M. Richardson. 2015. "On the Importance of Training Data Sample Selection in Random Forest Image Classification: A Case Study in Peatland Ecosystem Mapping." Remote Sensing 7 (7): 8489-8515. doi:10.3390/ rs70708489.

NASA JPL. 2013. NASA Shuttle Radar Topography Mission Global 1 Arc Second [Dataset]. NASA EOSDIS Land Processes DAAC. doi:10.5067/MEaSUREs/SRTM/ SRTMGL1.003.

Nguyen, L. H., D. R. Joshi, D. E. Clay, and G. M. Henebry. 2020. "Characterizing Land Cover/land Use from Multiple Years of Landsat and MODIS Time Series: A Novel Approach Using Land Surface Phenology Modeling and Random Forest Classifier." Remote Sensing of Environment 238: 111017. doi:10.1016/j.rse.2018.12.016.

Nistal-Nuño, B. 2017. "Segmented Regression Analysis of Interrupted Time Series Data to Assess Outcomes of a South American Road Traffic Alcohol Policy Change." Public Health 150: 51-59. doi:10.1016/j.puhe.2017.04.025.

Pekel, J.-F., A. Cottam, N. Gorelick, and A. S. Belward. 2016. "High-resolution Mapping of Global Surface Water and Its Long-term Changes." Nature 540 (7633): 418-422. doi:10.1038/nature20584.

Penfold, R. B., and F. Zhang. 2013. "Use of Interrupted Time Series Analysis in Evaluating Health Care Quality Improvements." Academic Pediatrics 13 (6): S38-S44. doi:10.1016/j.acap.2013.08.002.

Pinto, C. Teixeira, M. O. Haque, E. Micijevic, and D. L. Helder. 2019. "Landsats 1-5 Multispectral Scanner System Sensors Radiometric Calibration Update." IEEE Transactions on Geoscience and Remote Sensing 57 (10): 7378-94. doi:10.1109/TGRS.2019.2913106.

Shahtahmassebi, A. R., W. Chun, G. A. Blackburn, Q. Zheng, L. Huang, A. Shortridge, G. Shahtahmassebi, et al. 2018. “How Do Modern Transportation Projects Impact on Development of Impervious Surfaces via New Urban Area and Urban Intensification? Evidence from Hangzhou Bay Bridge, China." Land Use Policy 77: 479-497. doi:10.1016/j. landusepol.2018.05.059. 
Siachalou, S., G. Mallinis, and M. Tsakiri-Strati. 2015. "A Hidden Markov Models Approach for Crop Classification: Linking Crop Phenology to Time Series of Multi-sensor Remote Sensing Data." Remote Sensing 7 (4): 3633-3650. doi:10.3390/rs70403633.

Spiekermann, M., H. Youjoun, J. Yang, I. Burkhardt, F. Yan, Y. Xin, and S. Pauleit. 2013. "Hangzhou: Fast Urbanisation and High Population Growth." In Peri-urban Futures: Scenarios and Models for Land Use Change in Europe, edited by K. Nilsson, S. Pauleit, S. Bell, C. Aalbers, and T. A. Sick Nielsen, 307-337. Berlin, Heidelberg: Springer.

Thomas, P., and O. Daniel. 2013. "The Channel Tunnel: Transport Patterns and Regional Impacts." Journal of Transport Geography 31: 104-112. doi:10.1016/j. jtrangeo.2013.06.004.

Tian, B., W. Wenting, Z. Yang, and Y. Zhou. 2016. “Drivers, Trends, and Potential Impacts of Long-term Coastal Reclamation in China from 1985 to 2010." Estuarine, Coastal and Shelf Science 170: 83-90. doi:10.1016/j.ecss.2016.01.006.

Tokar, O., O. Vovk, L. Kolyasa, S. Havryliuk, and M. Korol. 2018. "Using the Random Forest Classification for Land Cover Interpretation of Landsat Images in the Prykarpattya Region of Ukraine." In 2018 IEEE 13th International Scientific and Technical Conference on Computer Sciences and Information Technologies (CSIT), 241-244. Lviv, Ukraine. doi:10.1109/STC-CSIT.2018.8526646.

Tucker, C. J. 1979. "Red and Photographic Infrared Linear Combinations for Monitoring Vegetation." Remote Sensing of Environment 8 (2): 127-150. doi:10.1016/0034-4257(79) 90013-0.

U.S. Geological Survey. 2020a. USGS EROS Archive - Landsat Archives - Landsat 4-5 TM Level-2 Data Products Surface Reflectance [Dataset]. Earth Resources Observation and Science (EROS) Center. doi:10.5066/ F7KD1VZ9. https://www.usgs.gov/centers/eros/science/ usgs-eros-archive-landsat-archives-landsat-4-5-tm-level -2-data-products-surface?qt-science_center_objects=0\#qtscience_center_objects.

U.S. Geological Survey. 2020b. USGS EROS Archive - Landsat Archives - Landsat 7 ETM+ Level-2 Data Products - Surface Reflectance [Dataset]. Earth Resources Observation and Science (EROS) Center. doi:10.5066/F7Q52MNK. https:// www.usgs.gov/centers/eros/science/usgs-eros-archivelandsat-archives-landsat-7-etm-level-2-data-productssurface?qt-science_center_objects=0\#qt-

science_center_objects

U.S. Geological Survey. 2020c. USGS EROS Archive - Landsat Archives - Landsat 8 OLI/TIRS Level-2 Data Products - Surface Reflectance [Dataset]. Earth Resources Observation and
Science (EROS) Center. doi:10.5066/F78S4MZJ. https:// www.usgs.gov/centers/eros/science/usgs-eros-archivelandsat-archives-landsat-8-olitirs-level-2-data-products?qtscience_center_objects=0\#qt-science_center_objects Verburg, P. H., W. Soepboer, A. Veldkamp, R. Limpiada, V. Espaldon, and S. S. A. Mastura. 2002. "Modeling the Spatial Dynamics of Regional Land Use: The CLUE-S Model." Environmental Management 30 (3): 391-405. doi:10.1007/s00267-002-2630-x.

Vermote, E., C. Justice, M. Claverie, and B. Franch. 2016. "Preliminary Analysis of the Performance of the Landsat 8/ OLI Land Surface Reflectance Product." Remote Sensing of Environment 185: 46-56. doi:10.1016/j.rse.2016.04.008.

Wu, K.-Y., Y. Xin-yue, Q. Zhi-fang, and Z. Hao. 2013. "Impacts of Land Use/land Cover Change and Socioeconomic Development on Regional Ecosystem Services: The Case of Fast-growing Hangzhou Metropolitan Area, China." Cities 31: 276-284. doi:10.1016/j.cities.2012.08.003.

Xie, Z., L. Xiuzhen, Y. Zhang, and S. Chen. 2018. "Accelerated Expansion of Built-up Area after Bridge Connection with Mainland: A Case Study of Zhujiajian Island." Ocean \& Coastal Management 152: 62-69. doi:10.1016/j. ocecoaman.2017.11.014.

Xu, H. 2006. "Modification of Normalised Difference Water Index (NDWI) to Enhance Open Water Features in Remotely Sensed Imagery." International Journal of Remote Sensing 27 (14): 3025-3033. doi:10.1080/ 01431160600589179.

Yang, L., X. Meng, and X. Zhang. 2011. "SRTM DEM and Its Application Advances." International Journal of Remote Sensing 32 (14): 3875-3896. doi:10.1080/01431161003786016.

Yavuz, F., U. Attanayake, and H. Aktan. 2017. “Economic Impact Analysis of Bridge Construction." Transportation Research Record: Journal of the Transportation Research Board 2630 (1): 95-102. doi:10.3141/2630-12.

Zha, Y., J. Gao, and N. Shaoxiang. 2003. "Use of Normalized Difference Built-up Index in Automatically Mapping Urban Areas from TM Imagery." International Journal of Remote Sensing 24 (3): 583-594. doi:10.1080/ 01431160304987.

Zheng, Q., H. Shan, L. Huang, X. Zheng, P. Yi, S. Amir Reza, S. Zhangquan, Y. Zhoulu, and W. Ke. 2016. "Assessing the Impacts of Chinese Sustainable Ground Transportation on the Dynamics of Urban Growth: A Case Study of the Hangzhou Bay Bridge." Sustainability 8 (7): 666. doi:10.3390/su8070666.

Zou, Y. 2020. Training Data For Random Forest Classification. (Version V1.0) [Dataset]. Zenodo. doi:10.5281/ zenodo.3960517. 